\title{
Angular measurements of the mandible in adults with temporomandibular joint disorders: a CBCT study
}

\author{
Seda Sertel Meyvacı ${ }^{1}$ (D), Duygu Göller Bulut ${ }^{2}$ (D), Ayşe Tuğçe Öztürk Koçak² (D), Handan Ankaralı ${ }^{3}$ (D) \\ ${ }^{1}$ Department of Anatomy, Faculty of Medicine, Bolu Abant İzet Baysal University, Bolu, Turkey \\ ${ }^{2}$ Department of Oral and Maxillofacial Radiology, Faculty of Dentistry, Bolu Abant İzet Baysal University, Bolu, Turkey \\ ${ }^{3}$ Department of Biostatistics and Medical Informatics, Faculty of Medicine, Istanbul Medeniyet University, Turkey
}

\begin{abstract}
Objectives: Temporomandibular disorder (TMD) is a degenerative musculoskeletal disease of unknown etiology, associated with morphological and functional deformities. The present study aimed to evaluate the angular parameters of the mandible in TMD patients with cone-beam computed tomography (CBCT) and to compare with healthy controls.

Methods: A total of 107 patients (54 in the TMD group and 53 in the control group) were included in the study. Ten angular measurements including right and left sides and 4 different length measurements were evaluated on CBCT images of both groups to eliminate individual differences. The differences between the two groups were examined using the significance test or Mann-Whitney $U$ test. Multiple linear regression analysis was used for a detailed examination of the relationship between parameters.
\end{abstract}

Results: The upper face width was significantly higher in the TMD group ( $p=0.004)$. After correcting for the upper face width value, there was a significant difference between the groups in terms of the right $\beta$ angle values $(p=0.001)$. The other differences were not significant ( $p>0.05$ ).

Conclusion: The decrease in the right $\beta$ angle in the TMD group can be interpreted as a result of the mechanical effect of masticatory muscle hyperactivity on the angular properties of the mandible in these patients.

Keywords: СВСТ; mandibular angles; mandibular morphometry; temporomandibular disorders

Anatomy 2020;14(3):185-191 @2020 Turkish Society of Anatomy and Clinical Anatomy (TSACA)

\section{Introduction}

The human body works like a puppet; deviations and distortions in any part of the structural system create ripple effects elsewhere. ${ }^{[1]}$ The temporomandibular joint (TMJ), is the only movable joint in the skull that connects the skull to the mandible and is responsible for jaw movements. ${ }^{[2]}$

The temporomandibular joint (TMJ) is a bicondylar joint formed between mandibular condyle of mandible and mandibular fossa of the temporal bone. ${ }^{[2,3]}$ Important functions such as eating and speaking are achieved through four different movements in two different axes in the TMJ. The factors that affect the TMJ include disorders of chewing muscles, joint disorders, chronic mandibular hypo-mobility, and developmental disorders. Temporomandibular disorder (TMD) is one of the degenerative musculoskeletal disorders associated with morphological and functional deformities. ${ }^{[4]}$

TMD affects important daily functions, such as feeding, and decrease the quality of daily life. Symptoms and signs of TMD include painful or painless joint sounds, deviation or deflection during movement, cranial, and/or muscular pain. ${ }^{[4,5]}$ Due to its multifactorial etiology, the treatment of TMD is still unclear. It can be thought in line with the data in the literature that; angular differences in the mandible may transmit the masticatory force to the TMJ in different unwanted ways, and this may cause joint disease due to the formation of abnormal 
forces in the joint area. ${ }^{[0-8]}$ Studies on TMJ patients have been focused on the mandibular condyle, mandibular morphology, and morphological changes in the joint disc. ${ }^{[-8]}$ However, the studies on the relationship of mandibular angular differences with TMD are limited. The aim of this study, therefore, was to evaluate the relationship between mandibular angular parameters and TMD via cone-beam computed tomography (CBCT) and show whether certain angles of the mandible will differ in the TMD patients from the healthy individuals.

\section{Materials and Methods}

CBCT images of 107 patients (23 males, 84 females) who admitted to the Bolu İzzet Baysal University Faculty of Dentistry, Oral and Maxillofacial Outpatient Clinic with complaints of pain and/or dysfunction in the TMJ region were examined. The patients had a suspicious bone-related pathology in the TMJ region. The patients who diagnosed as TMD but had no pathology that would affect the mandibular parameters were included in the patient group. The patients who neither had TMD nor any pathology that would affect the mandibular parameters were included in the control group. Accordingly, CBCT images of 54 patients (11 males and 43 females) were included in the TMD group and CBCT images of 53 patients ( 12 males and 41 females) were included in the control group.

The CBCT images were obtained with an I-CAT 3D Imaging System (Imaging Sciences International, Hatfield, PA, USA). All images were scanned with the same exposure parameters $(120 \mathrm{kVp}, 7 \mathrm{~mA}, 26.9 \mathrm{sec}$. scan time, $0.3 \mathrm{~mm} 3$ voxel size, and $10 \times 16 \mathrm{~mm}$ field of view; FOV). Images were combined with i-CAT Vision 1.9 software program (Imaging Sciences International LLC. Hatfield, PA, USA). The raw data of the images were transferred to the personal computer. All the images were evaluated with the same computer (Lenovo legion y520 laptop computer with $1920 \times 1080$ pixel resolution, 15.6inch monitor, 7th generation Intel ${ }^{\circledR}$ Core $^{\mathrm{TM}}$ i 7 and i5 processor). A single maxillofacial radiologist has reviewed all the images. A two-step controlled measurement was performed for each parameter, and the age and sex of each patient were also recorded.

Ten angles of the mandible were measured according to the landmarks reported previously ${ }^{[9-12]}$ and with slight modifications as:

- Right Gonion (Go) angle (Figure 1),

- Left Gonion angle (Figure 1),

- Gnathion (Gn) angle (between the transverse axis and mandibular line) (Figure 1),

- Mentomandibular angle (Figure 1),
- The angle between the right condylion (Co)-Go and Co-Gn ( $\alpha$ angle) (Co-Go-Gn triangle) (Figure 2),

- The angle between the left Co-Go and Co-Go ( $\alpha$ angle) (Co-Go-Gn triangle) (Figure 2),

- The angle between the right Go-Gn and Gn-Co $(\beta$ angle) (Co-Go-Gn triangle) (Figure 2),

- The angle between the left Gn-Co and Go-Gn ( $\beta$ angle) (Co-Go-Gn triangle) (Figure 2),

- The angle between right mandibular condyle - left mandibular condyle (Co-Co) (Figure 3a), and

- Go-Gn-Go angle (Figure 3b).

In addition to these measurements, the following length measurements were done to consider the individual differences. ${ }^{[1,13,14]}$

- Mandibular length (total length of the mandible),

- Bigonial width (Go-Go),

- Maximum cranial width (distance between right euryon (eu) and left eu), and

- Upper face width (distance between right frontomalar temporal point (fmt) and left fmt).

The sample size was calculated by power analysis. Using the hypothesis that there will be a moderate effect size between the two groups and the significance test of the difference between the two averages, Prior power is accepted as $80 \%$ and Type-I error is $5 \%$ for the effect size $\mathrm{w}=0.50$. It was determined that there should be at least 52 people in each group and at least 104 in total. G Power 3.1 program was used for sample size determination. Finally, 107 patients; 54 in TMD group and 53 in control group were included in the study.

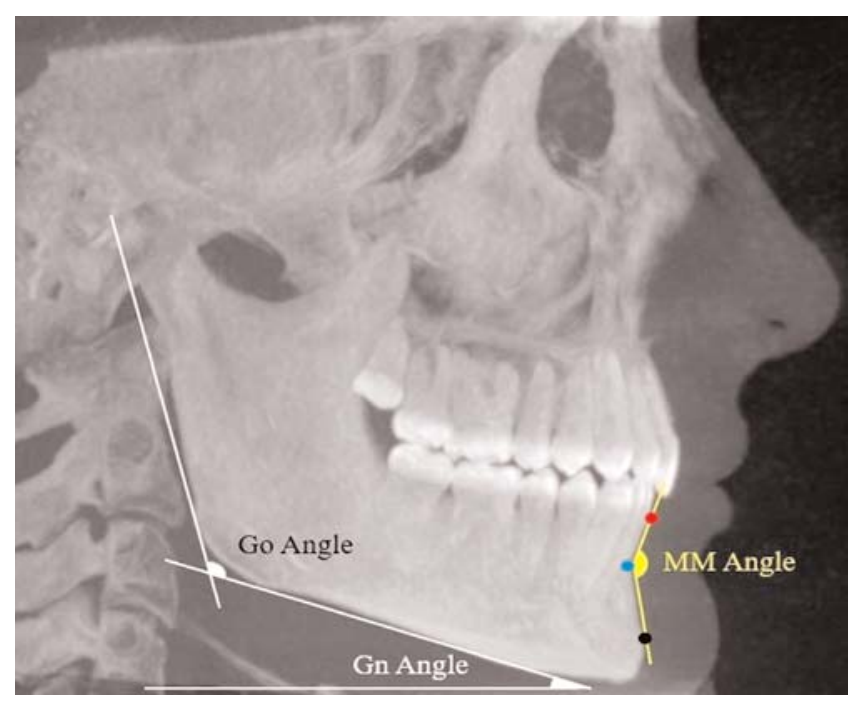

Figure 1. Right lateral cephalometric view. black dot: pogonion; blue dot: B point; Gn angle: gnathion angle; Go angle: gonion angle; MM angle: mentomandibular angle; red dot: infradentale point. 

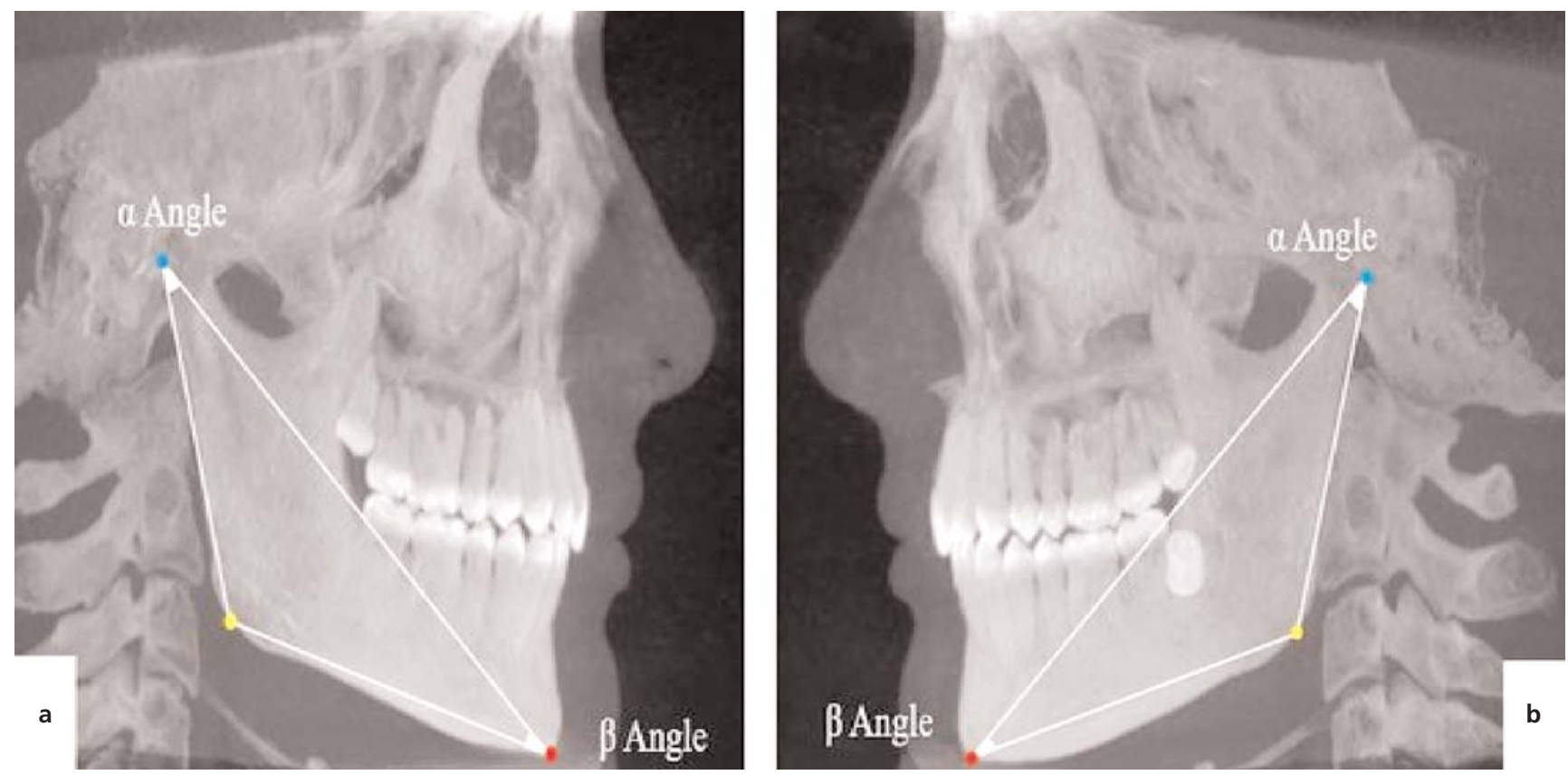

Figure 2. $\alpha$ and $\beta$ angles on right (a) and left (b) lateral cephalometric views. Blue dots: condlyon; red dots: gnathion; yellow dots: gonion.
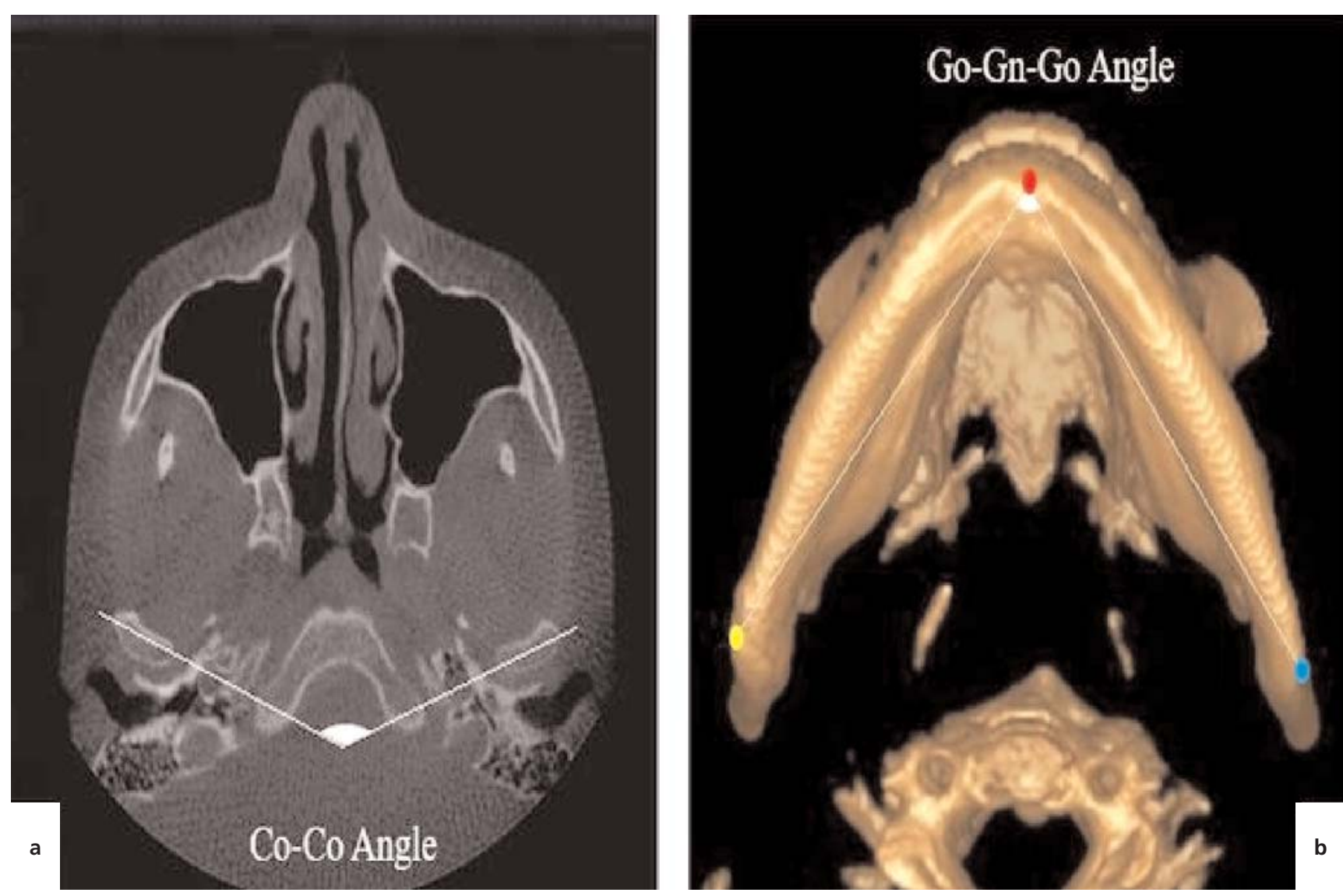

Figure 3. (a) axial section CBCT image; (b) 3D reconstruction image of CBCT obtained by i-CAT Vision 1.9 software program (Imaging Sciences International LLC. Hatfield, PA, USA), blue dot: left gonion; Co-Co angle: condylion-condylion angle; Go-Gn-Go angle: gonion-gnathion-gonion angle; red dot: gnathion; yellow dot: right gonion. 
Descriptive statistics of the obtained data were calculated as mean, standard deviation (SD), or median, and frequencies (n, \%). The compatibility of numerical features to normal distribution was examined with the Kolmogorov-Smirnov test. Independent samples t-test was used to compare the two groups in terms of normally distributed features, and others we used Mann-Whitney $\mathrm{U}$ test. A Chi-square test was used to examine the relationship between groups and categorical variables as gender. Pearson correlation coefficient was used to examine the relationship between numerical variables. Multiple linear regression analysis was used for a detailed examination of the relationship between parameters. All statistical analyses were made using SPSS (Statistical Package for Social Sciences) for Windows (Version 22, Chicago, IL, USA). The significance level was taken as $\mathrm{p}<0.05$.

\section{Results}

The mean age of patients in the TMD group was 31.5 years (range: $25.5-41.0$ years) and the control group was 35 years (range: $28.0-44.0$ years) years. There was no significant difference between the groups in terms of gender and age distribution ( $\mathrm{p}=0.775$ and $\mathrm{p}=0.141$ respectively).

Descriptive values of the measured angles by groups and comparison results of the two groups are given in Table 1. The statistical analyses showed that mean right $\beta$ angle was significantly higher in the control group $(p=0.006)$ and upper face width was significantly higher in the TMD group $(\mathrm{p}=0.004)$. The other differences were not significant.

Multiple regression analysis results corrected for upper face width values were shown in Table 2 . There was a significant difference between the groups in terms of the right $\beta$ angle values ( $\mathrm{p}=0.001$ ), after correcting for the upper face width value.

\section{Discussion}

In this retrospective study, we measured 10 different angles of the mandible in a group of TMD patients, including the right and left side of the mandible, and compared the measurements with healthy individuals to comment on whether these parameters differ among these two groups. There are numerous studies made on exploring the cause of the TMD ${ }^{[3,15-17]}$ however the etiology of TMD is still unclear and numerous factors can predispose this disorder.

Individual factors such as age, hormonal changes, and systemic status play a role in the etiology of TMD by affecting the host adaptive capacity. ${ }^{[18]}$ Systemic diseases may affect the fibrocartilage structure of TMJ. Therefore, the present study group was composed of individuals who did not have any disease that would affect bone metabo-

Table 1

Descriptive values of linear and angular measurements.

\begin{tabular}{|c|c|c|c|}
\hline & \multicolumn{2}{|c|}{ Group } & \multirow[b]{2}{*}{ p-value } \\
\hline & $\begin{array}{c}\text { TMD }(n=54) \\
\text { Mean } \pm \text { SD or median [25th-75th] }\end{array}$ & $\begin{array}{c}\text { Control }(n=53) \\
\text { Mean } \pm \text { SD or median [25th-75th] }\end{array}$ & \\
\hline Right gonion angle ${ }^{\circ}$ & $125.62 \pm 6.78$ & $124.50 \pm 7.42$ & 0.417 \\
\hline Left gonion angle ${ }^{\circ}$ & $125.63 \pm 4.97$ & $128.06 \pm 7.65$ & 0.055 \\
\hline Gnathion angle $^{\circ}$ & $20.29 \pm 4.35$ & $20.91 \pm 4.51$ & 0.472 \\
\hline Mentomandibular angle $^{\circ}$ & $141.04 \pm 7.69$ & $139.78 \pm 8.97$ & 0.436 \\
\hline Right $(\beta)$ angle ${ }^{\circ}$ & $26.19 \pm 3.31$ & $27.99 \pm 3.38$ & 0.006 \\
\hline Left $(\beta)$ angle ${ }^{\circ}$ & $26.51 \pm 3.78$ & $27.42 \pm 3.86$ & 0.221 \\
\hline Right $(\alpha)$ angle ${ }^{\circ}$ & $32.40 \pm 3.22$ & $33.02 \pm 5.31$ & 0.468 \\
\hline Left $(\alpha)$ angle ${ }^{\circ}$ & $30.91 \pm 3.22$ & $31.72 \pm 4.53$ & 0.288 \\
\hline Co-Co angle ${ }^{\circ}$ & $136.67 \pm 16.65$ & $137.09 \pm 12.23$ & 0.881 \\
\hline Go-Gn-Go angle ${ }^{\circ}$ & $76.49 \pm 5.78$ & $76.05 \pm 5.76$ & 0.698 \\
\hline Mandibular length (mm) & $88.33 \pm 5.95$ & $88.55 \pm 5.47$ & 0.849 \\
\hline Bigonial width (mm) & $97.04 \pm 6.42$ & $97.91 \pm 8.17$ & 0.540 \\
\hline Maximum cranial width* $(\mathrm{mm})$ & 144.25 [142.18-148.65] & $144.6[141.75-149.6]$ & 0.955 \\
\hline Upper face width* (mm) & 108.41 [104.5-111.3] & 103.8 [99.45-109.95] & 0.004 \\
\hline
\end{tabular}

*Data were not normally distributed. 
lism. Age is seen as a predisposing factor that increases the severity and frequency of the disease. ${ }^{[19,20]}$ In a study conducted on patients aged between 59-91 years old, Takano et al. ${ }^{[19]}$ revealed that the calcium content in articular disc increased with age and this may trigger pathologies of TMJ. Therefore, the age distribution in the present study were selected to minimize the age factor as; between 25.5 and 41.0 years in the patient group and between 28.0 and 44.0 years in the control group.

In a study conducted in 100 cases between the ages of $20-80$, it was reported that the Go angle was $125.19 \pm 6.27^{\circ}$ on the right side and $125.61 \pm 5.98^{\circ}$ on the left side. ${ }^{[21]}$ In another study, the mean Go angle was examined according to age groups and it was found as $122.45 \pm 5.34^{\circ} .{ }^{[2]}$ Although the Go angle in our study was compatible with the study of Acar et al., ${ }^{[21]}$ we saw that it was higher than the results of Sapanci et al. ${ }^{[22]}$ We think that this difference may be due to the different age ranges and different numbers of cases.

In another study conducted in 106 Koreans, the Go angle was found to be $118.68 \pm 14.39^{\circ}$ on the right side and $116.21 \pm 8.54^{\circ}$ on the left side with a mean age of $32.20 \pm 9.08 .^{[23]}$ Although the mean age of the cases in this study was similar to our study, the mean Go angle value in our study was found to be higher. The cases were of similar ages in those studies but the effect of ethnic origin may be a significant factor explaining the reason of different results. Different angular parameters of the mandible have been evaluated in various studies with different measurement techniques thus; the comparability of the study results may not always possible.
In the present study, upper face width was found to be higher in patients with TMD. Due to the effect of bruxism, excessive functioning of the masseter and temporal muscles may result in expansion of the zygomatic bone in the transverse direction and make a difference in the craniofacial skeletal structure. The idea of bone apposition in areas where the demand to withstanding bending force is increased has been demonstrated in many human and animal studies. ${ }^{[24]}$ In a morphometric study conducted on different populations, the upper face width was examined on dry skulls belonging to 100 males and 100 females with known gender and age at death. This value was found to be $92.04 \pm 4.76 \mathrm{~mm}$ in males with a mean age of 65.65 $(n=89)$ and $87.14 \pm 4.73$ in females with a mean age of 66.81 , and a difference between genders was reported $(\mathrm{p}<0.001){ }^{[14]}$ The result of the present study showed that the upper face width was larger than previously reported. We think that this situation may be caused by the difference in age and ethnic origin of the individuals among the studies.

According to Costen's mechanical displacement theory; occlusal derangement with consequent functional disturbance of the joint may lead to the direct eccentric positioning of the condyle in the glenoid fossa resulting in TMD. ${ }^{[25]}$ According to Reade's biomedical theory, TMD starts with trauma. ${ }^{[26]}$ As said by the neuromuscular theory of Ramjford, occlusal problems cause TMDs, loss of occlusal balance leads to uncoordinated muscles and spasms. ${ }^{[3]}$ Morphological features and dimensional differences in the dentomaxillofacial region could trigger TMD by causing trauma or indirectly by affecting chewing, myofascial activity. Based on these theories, we suggest

Table 2

Multiple regression analysis results corrected for upper face width.

\begin{tabular}{lcccc} 
& & & & \\
& & & \\
The dependent variable & $\mathbf{b}$ & Lower & Upper & p-value \\
\hline Right gonion angle $^{\circ}$ & -1.004 & -3.974 & 1.965 & 0.504 \\
\hline Left gonion angle $^{\circ}$ & 1.679 & -0.981 & 4.338 & 0.214 \\
\hline Gnathion angle $^{\circ}$ & 0.785 & -1.059 & 2.629 & 0.400 \\
\hline Mentomandibular angle $^{\circ}$ & -1.426 & -4.917 & 2.066 & 0.420 \\
\hline Right $(\beta)$ angle $^{\circ}$ & 2.372 & 1.024 & 0.001 \\
\hline Left $(\beta)$ angle & 0.908 & -0.680 & 0.260 \\
\hline Right $(\alpha)$ angle $^{\circ}$ & 0.265 & -1.532 & 2.495 & 0.770 \\
\hline Left $(\alpha)$ angle $^{\circ}$ & 0.140 & -1.430 & 2.063 & 0.860 \\
\hline Co-Co angle & 1.270 & -4.729 & 1.709 & 0.676 \\
\hline Go-Gn-Go angle & 0.448 & -1.912 & 2.808 & 0.707 \\
\hline
\end{tabular}


that the vertical dimensions of the occlusion may be affected due to tooth erosion resulting from temporal or masseter muscles hyperactivity caused by unilateral chewing or clenching in the TMD group, so that the angle $\beta$ decreased and these conditions may cause TMD by causing eccentric forces to be transmitted to the TMJ.

In juvenile idiopathic arthritis patients with unilateral TMJ involvement, Hsieh et al. ${ }^{[27]}$ reported that vertical and transverse asymmetry is more common, similarly Demant et al. ${ }^{[28]}$ revealed a significantly greater amount of asymmetry. Although unilateral or bilateral TMJ involvement is not known due to the retrospective design of this study, the results of the present study support these ideas. While the left $\beta$ angle did not differ, the right $\beta$ angle was lower in the TMD group and we suggest this condition may be due to the dominant chewing activity on the dominant side in chewing function, and this may be a sign of asymmetry and unilateral joint complaint in TMD group.

\section{Conclusion}

Although the pathophysiology of TMD is not fully understood, we think that the hyper-function of the masticatory muscles may have a mechanical effect on the angular properties of the mandible, In order to clarify this situation, more morphometric studies are needed in which the patient's symptoms, unilateral or bilateral joint involvement, presence of malocclusion, and the duration of TMD are evaluated in details.

\section{Conflict of Interest}

The authors have no conflicts of interest to declare regarding the materials or methods in this study or the findings specified in this paper.

\section{Author Contributions}

SSM: project development, writing the manuscript, critical revision of the text; DGB: project development, writing the manuscript, editing and critical revision of the text; ATÖK: data collection, writing the manuscript; HA: data analysis.

\section{Ethics Approval}

This study was approved by the Bolu Abant İzzet Baysal University, Clinical Researches Ethics Committee (Decision No: 2020/82, Date: 07.04.2020).

\section{Funding}

The authors declare no financial support for this study.

\section{References}

1. Piccin CF, Pozzebon D, Scapini F, Corrêa EC. Craniocervical posture in patients with obstructive sleep apnea. Int Arch Otorhinolaryngol 2016;20:189-95.

2. Joy TE, Tanuja S, Pillai RR, Dhas Manchil PR, Raveendranathan R. Assessment of craniocervical posture in TMJ disorders using lateral radiographic view: a cross-sectional study. Cranio 2019:1-7. doi:10.1080/08869634.2019.1665227

3. Bhat S. Etiology of temporomandibular disorders: the journey so far. International Dentistry SA 2010;12:88-92.

4. Murphy MK, MacBarb RF, Wong ME, Athanasiou KA. Temporomandibular disorders: a review of etiology, clinical management, and tissue engineering strategies. Int J Oral Maxillofac Implants 2013;28:393-414.

5. Wieckiewicz M, Boening K, Wiland P, Shiau YY, ParadowskaStolarz A. Reported concepts for the treatment modalities and pain management of temporomandibular disorders. J Headache Pain 2015;16:106.

6. Ferreira FM, Cézar Simamoto-Júnior P, Soares CJ, Ramos A, Fernandes-Neto AJ. Effect of occlusal splints on the stress distribution on the temporomandibular joint disc. Braz Dent J 2017;28:3249.

7. Liu MQ, Lei J, Han JH, Yap AU, Fu KY. Metrical analysis of disccondyle relation with different splint treatment positions in patients with TMJ disc displacement. J Appl Oral Sci 2017;25:483-9.

8. Shokri A, Zarch HH, Hafezmaleki F, Khamechi R, Amini P, Ramezani L. Comparative assessment of condylar position in patients with temporomandibular disorder (TMD) and asymptomatic patients using cone-beam computed tomography. Dent Med Probl 2019;56:81-7

9. Dhaka P, Mathur E, Sareen M, Baghla P, Modi A, Sobti P. Age and gender estimation from mandible using lateral cephalogram. CHRISMED Journal of Health and Research. 2015;36:208-11.

10. Amin WM. Osteometric assessment of various mandibular morphological traits for sexual dimorphism in jordanians by discriminant function analysis. International Journal of Morphology 2018;36:64250 .

11. Naikmasur VG, Shrivastava R, Mutalik S. Determination of sex in South Indians and immigrant Tibetans from cephalometric analysis and discriminant functions. Forensic Sci Int 2010;197:122.e1-6.

12. Wangai $L$, Mandela $P$, Butt F. Horizontal angle of inclination of the mandibular condyle in a Kenyan population. Anatomy Journal of Africa 2012;1:46-9.

13. Vinay G, Mangala Gowri S, Anbalagan J. Sex determination of human mandible using metrical parameters. J Clin Diagn Res 2013;7:2671-3.

14. Mahakkanukrauh P, Sinthubua A, Prasitwattanaseree S, Ruengdit S, Singsuwan P, Praneatpolgrang S, Duangto P. Craniometric study for sex determination in a Thai population. Anat Cell Biol 2015;48: 275-83.

15. Lövgren A, Österlund C, Ilgunas A, Lampa E, Hellström F. A high prevalence of TMD is related to somatic awareness and pain intensity among healthy dental students. Acta Odontol Scand 2018;76:38793.

16. Stegenga B, de Bont LG, Boering G. Osteoarthrosis as the cause of craniomandibular pain and dysfunction: a unifying concept. J Oral Maxillofac Surg 1989;47:249-56.

17. Ismail F, Eisenburger M, Lange K, Schneller T, Schwabe L, Strempel J, Stiesch M. Identification of psychological comorbidity in TMD-patients. Cranio 2016;34:182-7. 
18. Tanaka E, Detamore MS, Mercuri LG. Degenerative disorders of the temporomandibular joint: etiology, diagnosis, and treatment. J Dent Res 2008;87:296-307.

19. Takano Y, Moriwake Y, Tohno Y, Minami T, Tohno S, Utsumi M, Yamada M, Okazaki Y, Yamamoto K. Age-related changes of elements in the human articular disk of the temporomandibular joint. Biol Trace Elem Res 1999;67:269-76.

20. Tanaka E, Sasaki A, Tahmina K, Yamaguchi K, Mori Y, Tanne K. Mechanical properties of human articular disk and its influence on TMJ loading studied with the finite element method. J Oral Rehabil 2001;28:273-9.

21. Acar M, Alkan SB, Tolu I, Arslan FZ, Caglan F, Vermez H, Sasmaz S, Okutan S. Morphometric analysis of mandibula with MDCT method in Turkish population. Asian Journal of Biomedical and Pharmaceutical Sciences 2017;7(62):13-5.

22. Sapanci I, Şahin HO, Doğan Ö. Investigation of relationship between age and gender with mandibular parameters: a retrospective study. Selcuk Dental Journal 2019;6:328-34.

ORCID ID:

S. Sertel Meyvacı 0000-0002-9450-145X D. Göller Bulut 0000-0003-4260-2520 A. T. Öztürk Koçak 0000-0002-2728-5793; H. Ankaralı 0000-0002-3613-0523

deomed.
23. Kim YH, Kang SJ, Sun H. Cephalometric angular measurements of the mandible using three-dimensional computed tomography scans in Koreans. Arch Plast Surg 2016;43:32-7.

24. Sella-Tunis T, Pokhojaev A, Sarig R, O’Higgins P, May H. Human mandibular shape is associated with masticatory muscle force. Sci Rep 2018;8:6042.

25. Michael LA. Jaws revisited: Costen's syndrome. Ann Otol Rhinol Laryngol 1997;106:820-2.

26. Reade PC. An approach to the management of temporomandibular joint pain-dysfunction syndrome. J Prosthet Dent 1984;51:91-6.

27. Hsieh YJ, Darvann TA, Hermann NV, Larsen P, Liao YF, Kreiborg S. Three-dimensional assessment of facial morphology in children and adolescents with juvenile idiopathic arthritis and moderate to severe TMJ involvement using 3D surface scans. Clin Oral Investig 2020;24:799-807.

28. Demant S, Hermann NV, Darvann TA, Zak M, Schatz H, Larsen P, Kreiborg S. 3D analysis of facial asymmetry in subjects with juvenile idiopathic arthritis. Rheumatology (Oxford) 2011;50:586-92.

Correspondence to: Duygu Göller Bulut, Dt, PhD Department of Oral and Maxillofacial Radiology, Faculty of Dentistry, Bolu Abant Izzet Baysal University, Bolu, Turkey Phone: +90 3742541000 (8350) e-mail: duygugoller@hotmail.com Conflict of interest statement: No conflicts declared.

This is an open access article distributed under the terms of the Creative Commons Attribution-NonCommercial-NoDerivs 4.0 Unported (CC BY-NCND4.0) Licence (http://creativecommons.org/licenses/by-nc-nd/4.0/) which permits unrestricted noncommercial use, distribution, and reproduction in any medium, provided the original work is properly cited. How to cite this article: Sertel Meyvacı S, Göller Bulut D, Öztürk Koçak AT, Ankaralı H. Angular measurements of the mandible in adults with temporomandibular joint disorders: a CBCT study. Anatomy 2020;14(3):185-191. 